\title{
El juego estratégico de la seguridad ciudadana en Argentina (1996-2011)
}

\author{
Gabriel CONSTANTINO \\ Universidad Nacional de San Martín \\ gcostant76@gmail.com
}

Recibido: 25/03/2015

Aceptado: 12/05/2015

\section{Resumen}

El objetivo del trabajo es reconstruir el juego estratégico que hay detrás de la formulación de las políticas de seguridad ciudadana en cuatro provincias de Argentina entre 1996 y 2011. La hipótesis central es que los gobernadores son los actores que tienen las facultades y el interés de formular una política de seguridad de izquierda o de derecha según su plan de campaña, que responde a otros condicionantes que no son los supuestos intereses policiales: principalmente la ideología del ejecutivo nacional y la del elector medio. La contrastación de dicha hipótesis instruye sobre el juego estratégico de la formulación de las políticas de seguridad provinciales y sobre la autonomía relativa de la policía y el sistema penal en Argentina.

Palabras clave: Políticas de seguridad ciudadana, - Gobernadores, Policía.

\section{The strategic game of citizen security in Argentina (1996-2011)}

\begin{abstract}
The aim of this article is reconstruct the strategic game behind the formulation of citizen security policies in the main Argentine's provinces between 1996 and 2011. The central hypothesis of this work consider that governors are the actors with capacities and interests to pursue a policy of security of left or right according to their plan of campaign, which responds to other factors which are not the alleged police interests: mainly the ideology of the national executive and the location of the median voter. The corroboration of this hypothesis instructs on the strategic game behind securities policies and the relative autonomy of the police and the penal system in Argentina.
\end{abstract}

Key words: Citizen Security Policies, Governors, Police.

\section{Introducción}

A finales de 2013, una serie de protestas policiales iniciadas en Córdoba se propagaron por casi todas las provincias argentinas. Según el director del Centro de Estudios Nueva Mayoría, las revueltas de las fuerzas de seguridad fueron las más extendidas en la historia de nuestro país: «La mitad de las provincias tuvieron protestas policiales en una misma semana, pero además estas provincias tienen el $80 \%$ de la población total» 
(La Nación, 2013). Durante los casi quince días que duraron las protestas policiales, las provincias afectadas sufrieron saqueos, muertes violentas, y un aumento de la sensación de inseguridad y de desgobierno democrático (cfr. Clarín, 2013).

En este contexto, varios periodistas, políticos y especialistas en seguridad argumentaron en los principales medios de comunicación que las revueltas acontecían porque la policía es una organización con una alta capacidad para independizarse del poder político y perseguir sus propios intereses, muchas veces ilegales y represivos. Por ejemplo, León Arslanián, ministro de seguridad bonaerense en dos ocasiones, declaró que los gobiernos provinciales debían implementar reformas que les devuelvan la conducción de las fuerzas de seguridad y terminen «con la autonomía y el autogobierno policial» (2014: 12). Marcelo Sain, ex director de la Policía de Seguridad Aeroportuaria, y quizás el especialista en seguridad más citado del país, sostuvo de manera complementaria que el problema de las protestas policiales se explicaba porque los gobiernos democráticos habían delegado cada vez más poder en las fuerzas de seguridad (Perfil, 2013).

Es de notar que esta interpretación de los sucesos de diciembre de 2013 responde a la perspectiva predominante en el análisis académico de la policía en Argentina (Sain, 2002 y 2008; Galeano, 2005; Camou y Moreno, 2005; Arslanián, 2008). Según el libro clásico de Marcelo Sain publicado en 2002, Seguridad, democracia y reforma del sistema policial en la Argentina, la policía se ha hecho cargo tradicionalmente de la administración de la seguridad pública y, en particular, de la formulación e implementación de la política de seguridad interior, y de su conducción estratégica y operativa. La policía cuenta «con la potestad para definir sus propias funciones, misiones y fines institucionales y para proporcionarse sus propios criterios y medios para cumplirlos. En efecto, la autonomía política de las agencias policiales les permite sustentar una marcada independencia doctrinal, orgánica y funcional frente al gobierno estatal y frente a la sociedad política y civil, y, a partir de ello, desenvolver en forma autosustentada ciertas modalidades organizativas y de funcionamiento y ciertas prácticas institucionales regulares» (2002: 41).

Ahora bien, en contraposición a esta perspectiva tan extendida, algunos estudios históricos argumentan que la policía ha sufrido muchas intervenciones discrecionales del poder político en su organización y funcionamiento (Frederic, 2008; Barreneche, 2009 y 2010; Rodrigo, 2013; Costantino, 2013). De hecho, existen varios antecedentes que testimonian que el diseño constitucional y las prácticas políticas argentinas han aceptado una gran intervención de los ejecutivos en la estructura y composición de las fuerzas de seguridad, incluso mayor que la sucedida en otras burocracias públicas (vg. justicia, educación, etc.). Algunos ejemplos importantes de esta intervención discrecional son los repetidos desplazamientos de las cúpulas policiales y las consecuentes purgas que ha sufrido esta institución, además de la consecuente prohibición de la sindicalización de sus miembros.

Estas visiones divergentes sobre la autonomía policial llevan a revisar en qué medida la policía es independiente del poder político, en qué medida tiene intereses propios y recursos para llevarlos a cabo. En el contexto de esta investigación, la pregunta específica es ¿qué actores tienen la capacidad y el interés de determinar la formulación de la política de seguridad en una jurisdicción? Esta pregunta abre una indagación rele- 
vante porque la formulación de la política de seguridad ciudadana puede ser analizada como variable, y porque tiene vinculaciones importantes tanto con el funcionamiento de las burocracias policiales y penales como con la interacción entre los actores principales de la dinámica política argentina.

Para ensayar una respuesta a la pregunta formulada, elaboramos un marco teórico basado en literatura clásica (Downs, 1957) y contemporánea (Calabresi, 1995; Ornstein y Mann, 2000) de la ciencia política, literatura que permite indagar en la lógica de la competencia partidaria y en su vínculo con la formulación de las políticas de seguridad en las provincias argentinas. Luego, analizamos los procesos de formulación de las políticas de seguridad en las cuatro provincias principales de Argentina entre 1996 y $2011^{1}$, a fin de corroborar si la hipótesis de la teoría de la autonomía policial o la elaborada a partir de nuestro marco teórico, se ajusta mejor a la interpretación de los sucesos.

Finalmente, a partir de la contrastación realizada, explicamos cómo el análisis del juego estratégico de la seguridad ciudadana provincial puede aportar a la construcción de enfoques relacionales en el estudio del funcionamiento de la policía y del sistema penal. En este sentido, coincidimos con Sabina Frederic que la construcción de dichos enfoques relacionales será fundamental para desafiar los prejuicios más difundidos en la academia sobre la gestión de la policía y del sistema penal en Argentina $^{2}$, facilitando el diálogo razonable entre los actores clave de los procesos de formulación e implementación de políticas de seguridad ciudadana.

\section{La formulación de las políticas de seguridad ciudadana}

En general, la opinión pública y gran parte de la literatura especializada entienden por política de seguridad ciudadana al conjunto de las acciones gubernamentales que tienen como objetivo mejorar la prevención, la investigación y el castigo de los delitos en determinada jurisdicción. ${ }^{3}$ Es de notar que los trabajos académicos suelen referirse en vez de a la política de seguridad, a las reformas de la policía y/o del sistema penal (cfr. Rico, 1998; Salles Kobilanski, 2011; González, 2007; Saín, 2002). Pero el objeto

${ }^{1}$ Las provincias han sido elegidas puesto que sus gobiernos dirigen las burocracias policiales y penales más grandes de Argentina, además de ser las más pobladas. El recorte temporal se debe a cuestiones vinculadas a la accesibilidad a información secundaria sobre datos legales y burocráticos provinciales. Asimismo, consideramos que el recorte a nivel jurisdiccional y temporal resulta en una muestra representativa de lo que sucede en la formulación de las políticas de seguridad nacional en otras provincias argentinas.

${ }^{2}$ Como explica Frederic (2008: 49), «es interesante advertir cómo insiste la visión según la cual gran parte del comportamiento policial visto como un desvío de la norma se debe a su autonomía profesional y política, y por consiguiente a la disociación entre la moral policial y la moral societal». Compartimos con Frederic su perspectiva sobre las consecuencias teóricas y prácticas de esta visión (ver Conclusiones).

${ }^{3}$ Según Diego Galeano (2005: 96), «las políticas públicas se definen usualmente como un proceso que envuelve una serie de objetivos, decisiones y acciones llevadas a cabo por un gobierno con el propósito de atender los problemas que en un momento determinado la ciudadanía considera prioritarios». 
de análisis suele ser el mismo: cambios normativos y administrativos producidos por los gobiernos de turno que hacen a la gestión de la seguridad. Por ejemplo, la promulgación de leyes penales, la elaboración de cambios administrativos y reglamentarios, la inversión de recursos económicos y humanos para llevar adelante los programas ideados en las leyes y reglamentos, etc. ${ }^{4}$

Si seguimos la literatura de la ciencia de las políticas públicas más contemporánea, lo que la opinión pública y muchos investigadores sociales llaman políticas de seguridad o reformas del sistema de seguridad, en realidad hace referencia a la formulación de la política pública: a la gran decisión en la cúspide del estado (Aguilar Villanueva, 1992: 24 y 25). Pues el concepto de política pública, la política pública como proceso, según esta literatura, debe incorporar las muchas y diversas decisiones de los actores participantes, gubernamentales y extra gubernamentales, que en sus diversas interacciones preparan y condicionan la decisión central y su implementación (cfr. Marsh y Rhodes, 1992; Jordana, 1995). Siguiendo este punto de vista, sería fundamental para analizar las políticas de seguridad el accionar de civiles, agentes judiciales, policiales, penitenciarios, a políticos y líderes de opinión, que con sus comportamientos afectan sustancialmente la prevención, la investigación y el castigo de los delitos. En efecto, sería importante sumar al análisis fenómenos como las protestas policiales, judiciales y penitenciarias; las olas de noticias sobre inseguridad o corrupción policial; los cambios en los mercados de los delitos; etc.

Ahora bien, existen buenas razones para comenzar el análisis focalizándonos en las decisiones de la cúspide del Estado, en cómo se formulan las políticas de seguridad. Si bien los enfoques inclusivos de muchos actores suelen parecer más pertinentes a la hora de analizar determinada política pública en un momento determinado, cuando se los intenta conceptualizar y operacionalizar para que produzcan conocimiento con capacidad de vuelo más allá de la descripción de un momento puntual, cuando se lo trata de convertir en un enfoque parsimonioso, pierden fácilmente el eje. Debido a la complejidad del análisis del proceso de las políticas públicas, el analista debe encontrar alguna forma de simplificar la situación a fin de poder encontrar el grupo reducido de relaciones críticas entre elementos que subyace a la complejidad desconcertante de los fenómenos para describir y explicar algo. ${ }^{5}$ Considero que una buena estrategia para comenzar este proceso de simplificación necesario es focalizarse en los gobiernos de turno, en sus recursos e intereses.

\footnotetext{
${ }^{4}$ Una curiosidad de la literatura argentina es que denomina reformas del sistema policial y penal, en general, sólo a aquellos cambios normativos y administrativos que se ajustan a un modelo progresista o de izquierdas, mientras que los cambios de derecha se denominan contrarreformas.

5 En este punto nos acercamos al enfoque epistemológico convencional que uno puede encontrar en las propuestas de diseño de investigación de King (2000) o Sabatier (2010). En palabras de Sabatier (2010: 11) «el supuesto ontológico fundamental de la ciencia es que existe un grupo reducido de relaciones críticas entre elementos que subyace a la complejidad desconcertante de los fenómenos. Estas relaciones tiene que ser captadas mediante conceptos y proposiciones relativamente claros e internamente coherentes, que identifiquen en forma precisa factores causales, y generan hipótesis falsables y suficientemente amplias en su alcance».
} 
Dicha focalización es pertinente porque en la mayoría de las organizaciones políticas contemporáneas, el gobierno sigue siendo el actor central del accionar coordinado con resultados sustantivos en la prevención, investigación y castigo de los delitos a través del tiempo. Las leyes, las reglamentaciones, las órdenes y las declaraciones oficiales de estas instituciones gubernativas suelen ser un elemento importante que afecta los recursos económicos y las personas que gestionan la provisión de esos bienes públicos. En efecto, tienen un impacto sustantivo en los comportamientos y discursos que hacen a la puesta en práctica de la política pública. Además, estas decisiones son fundamentales también para que el gobierno le comunique al electorado (a la opinión pública) su posición y su estrategia para enfrentar el problema del delito, logrando aumentar la popularidad o disminuyéndola. ${ }^{6}$ Esto tiene consecuencias políticas relevantes pues repercute tanto en la carrera electoral para mantenerse en el gobierno como en la aquiescencia y en la colaboración de intendentes, comisarios, jueces y fiscales hacia la política de seguridad.

Quizás por todo lo dicho es que, más allá de las recomendaciones de la literatura experta de la ciencia de las políticas públicas, los funcionarios, investigadores y periodistas especializados en temas de seguridad continúan centrando sus análisis en las acciones del gobierno. Estos especialistas en temas vinculados a las políticas (o reformas) en el área de seguridad suele clasificar las medidas según un criterio ideológico, según se acercan a modelos seguritarios de izquierda o de derecha (Rico, 1997; Rico y Chinchilla, 2002; Sain, 2002; González, 2007; Salles Kobilanski, 2011). ${ }^{7}$ Este criterio ideológico suele tener como dimensiones: a) la forma de gobierno del sistema de seguridad y b) las acciones a emprender para: i) prevenir el delito, ii) investigar y enjuiciar a los presuntos delincuentes y iii) castigar a los criminales.

Las políticas de seguridad ciudadana situadas cerca del polo izquierdo se caracterizan por promover un modelo participativo de dirección y control de la política de seguridad (Sain, 2002; Camou y Moreno, 2005; Arslanián, 2008). No sólo proponen elegir por medio del voto a los gobernantes del sistema penal, sino que proyectan otros mecanismos de participación de la ciudadanía en la elaboración y en la implementación de la política de seguridad (funcionarios civiles a cargo del ministerio y de la policía, foros de seguridad, audiencias públicas, defensores públicos contra la inseguridad y el maltrato policial, fiscalías especializadas, etc.).

En cuanto al contenido de la política de seguridad, las propuestas de izquierda subrayan que la policía y el sistema penal son un instrumento de eficacia limitada para

${ }^{6}$ En efecto, las políticas de seguridad ciudadana se destacan respecto a otras políticas públicas provinciales porque la responsabilidad institucional del gobernador sobre la burocracia policial y penitenciaria es más directa que sobre otras (vg. salud, educación, etc.), y porque la tematización creciente de los delitos en los medios de comunicación hacen a la política de seguridad un elemento fundamental de la reputación del gobernador. Una consecuencia de esto es que la formulación de las políticas de seguridad está fuertemente asociada con la estrategia de campaña, además de con distintos sucesos criminales que conmocionan a la opinión pública y que obligan a tomar posición al gobierno de la provincia (ver apartado 3).

7 Otra curiosidad de la literatura argentina es que suele denominar a las políticas de centro derecha como políticas populistas punitivas, autoritarias, represivas, etc. Mientras que a las de centro izquierda las denomina democráticas, ciudadanas, garantistas. 
prevenir el delito. Existen otros factores como la educación familiar y escolar, el trabajo, las relaciones sociales y la opinión pública, que juegan un papel igual o más relevante para desincentivar el crimen. Más a la izquierda, se sostiene que si no se combate la pobreza y la desigualdad socioeconómica estructural, la violencia y el delito son inevitables. En efecto, estos modelos proponen políticas integrales contra la inseguridad que ayuden a los sectores más vulnerables a organizarse laboral y socialmente, posibilitándoles el acceso a buenos sistemas de salud, educativos, culturales, deportivos y recreativos, generando también con ello la posibilidad de su organización política (Ciafardini, 2005; Centro de Estudios Legales y Sociales -CELS-, 2004).

Una segunda característica del contenido de las propuestas seguritarias de izquier$d a$ es que consideran que la policía y el sistema penal son más un peligro que una necesidad para los derechos de los ciudadanos. De ahí la importancia de estipular mecanismos de control del poder de disuasión, investigación y sanción a los presuntos criminales, políticas garantistas que materializan el derecho a un debido proceso en la verificación de los delitos y en su enjuiciamiento y penalización (Diez Ripollés, 2004; Pérez Cepeda, 2006). Por otra parte, la persecución penal debe ir más allá del delito común y debe enfrentar al delito de alta complejidad y de corrupción, que son los que debilitan en mayor medida al Estado y su capacidad de implementar políticas integrales (CELS, 2004; Centro de Estudios de Justicia de las Américas -CEJA-, 2005).

Finalmente, las políticas de seguridad de izquierda resaltan que las sanciones penales tienen que respetar la dignidad humana. Los castigos deben ser proporcionales al delito cometido (no deben castigar por demás al individuo por una cuestión simbóli$\mathrm{ca} /$ disuasoria), y deben estar orientados a la resocialización del delincuente. En general, las personas que comparten esta visión de la política seguritaria desconfían de la cárcel ya que no logra éste fin último (Diez Ripollés, 2004; Pérez Cepeda, 2006; Zaffaroni, 2009).

En oposición a las políticas de izquierda, las políticas seguritarias cercanas al polo derecho, sostienen que el gobierno del sistema penal debe estar en manos de miembros o representantes de esta burocracia o de las fuerzas armadas. Es decir, de especialistas en el manejo de la violencia legítima. Luego, la estructura organizativa debe ser centralizada y jerárquica para maximizar su capacidad operativa.

En cuanto al contenido de la política de seguridad, las posiciones de derecha sostienen que la policía y el sistema penal son un instrumento eficaz para prevenir el delito porque disuaden, aíslan e inocuizan a los delincuentes, con un castigo lo suficientemente penoso. Más allá de los distintos factores que afectan a la comisión de delitos, consideran que el sistema de seguridad es un elemento clave y necesario, pues siempre existen en las sociedades, por más igualitarias que sean, gente que ejerce violencia arbitraria sobre la integridad física y los bienes de otras personas o de todos.

Respecto al tema de la persecución penal, los defensores de las políticas seguritarias de derecha consideran que el sistema de seguridad es más una necesidad que un peligro para los derechos de los ciudadanos. Pues mucho más peligrosos son las personas que han devenido enemigos de la sociedad debido a su reincidencia en el delito y a su integración en organizaciones delictivas estructuradas. Frente a este tipo de individuo que no ofrece la mínima seguridad cognitiva de un comportamiento personal acorde con el ordenamiento jurídico, la persecución penal debe ser eficaz con el fin de 
aislarlos e inocuizarlos. En efecto, desde esta perspectiva las garantías y derechos procesales pasan a segundo plano, por ejemplo, reduciéndose las exigencias de licitud y admisibilidad de la prueba, de investigación secreta y clandestina, se amplían los plazos de detención policial y de prisión preventiva para el cumplimiento de fines investigadores, incluso se admiten las vejaciones a los presuntos delincuentes y delincuentes en función de controlar su peligrosidad y la de otros (Diez Ripollés, 2004; Pérez Cepeda, 2006).

Sobre el castigo, estas posturas plantean las sanciones penales tienen que aislar e inocuizar al delincuente, e intimidar a la delincuencia en general. Vinculado a esto, las cárceles son un recurso eficiente y económico para el castigo, el control y la intimidación de los delincuentes. Además, el juicio y el castigo penal son importantes porque recuerdan el significado de la justicia retributiva, que hay que cumplir con las normas y el papel de un gobierno efectivo para que esto suceda (Diez Ripollés, 2004; Pérez Cepeda, 2006).

En el medio de estos dos paradigmas de políticas de seguridad se encuentran los discursos de centro. Estos discursos combinan de manera más o menos coherente argumentos y políticas de derecha y de izquierda. De hecho, muchos políticos y actores sociales relevantes proponen acciones integrales o bienestaristas para mejorar la situación de los sectores más vulnerables y marginales, a la vez que señalan la importancia de políticas punitivas que castiguen y/o inocuicen a aquellas personas que a pesar del esfuerzo del Estado, deciden robar, matar, etc. (Álvarez et al., 2013). Respecto de la persecución penal, los formuladores de este discurso se muestran comprometidos con la investigación criminal del delito común, pero también con la delincuencia organizada y la corrupción. Finalmente, consideran que lo ideal sería instrumentar penas que promuevan la resocialización de los delincuentes. Aún así, y dado que no hay recetas infalibles para lograr esto, la cárcel es una pena conveniente -en la medida en que es proporcional al delito cometido-, pues permite la inocuización temporal del delincuente, mientras se prueban distintas experiencias resocializadoras.

\footnotetext{
${ }^{8} \mathrm{Al}$ lector atento podría parecerle que esta clasificación de las políticas públicas de corte ideológico niega o soslaya aspectos que habría que poner en primer plano en el análisis y en la discusión de las políticas de seguridad. Por ejemplo, la condición laboral de los funcionarios del sistema policial y penal vis a vis otras profesiones y vis a vis otras jurisdicciones y épocas, el nivel de eficiencia que uno puede encontrar en el desempeño de los funcionarios del sistema policial y penal vis a vis otras profesiones y vis a vis otras jurisdicciones y épocas. Sin embargo, la dificultad actual de conseguir información razonablemente exhaustiva y sin sesgos sobre estos asuntos impide avanzar en nuevas clasificaciones más pertinentes y menos sesgadas. Por otra parte, las diferencias en la «inversión» de normas, recursos económicos y recursos humanos tienen consecuencias que son relevantes desde el punto de vista del análisis político, tanto en el funcionamiento de la política de seguridad como en la carrera electoral de los gobernadores.
} 


\begin{tabular}{|c|c|c|c|}
\hline & IZQUIERDA & CENTRO & DERECHA \\
\hline $\begin{array}{l}\text { SUJETO DE LA } \\
\text { POLITICA } \\
\text { SEGURITARIA }\end{array}$ & La ciudadanía. & $\begin{array}{l}\text { Los poderes politicos } \\
\text { clásicos. }\end{array}$ & $\begin{array}{l}\text { Miembros del } \\
\text { sistema penal. }\end{array}$ \\
\hline $\begin{array}{l}\text { PREVENCIÓN } \\
\text { DEL DELITO }\end{array}$ & $\begin{array}{l}\text { Basada en políticas } \\
\text { integrales. La } \\
\text { estructura organizativa } \\
\text { de la policía debe tener } \\
\text { múltiples mecanismos } \\
\text { de accountability. }\end{array}$ & $\begin{array}{l}\text { Basada en politicas integrales } \\
\text { y en políticas } \\
\text { punitivas/disuasorias. }\end{array}$ & $\begin{array}{l}\text { Basadas en políticas } \\
\text { punitivas/disuasorias. } \\
\text { La estruetura } \\
\text { organizativa de la } \\
\text { policía debe ser } \\
\text { centralizadla y } \\
\text { jerárquica para } \\
\text { maximizar su } \\
\text { capacidad operativa. }\end{array}$ \\
\hline \multirow{2}{*}{$\begin{array}{l}\text { INVESTIGACIÓN } \\
\text { DE PRESUNTOS } \\
\text { CRIMINALES }\end{array}$} & $\begin{array}{l}\text { Persecución penal } \\
\text { respetuosa de las } \\
\text { garantias al debiclo } \\
\text { proceso. }\end{array}$ & $\begin{array}{l}\text { Persecución penal respetuosa } \\
\text { de las garantias del debido } \\
\text { proceso e interesada en la } \\
\text { eficacia en la resolución de } \\
\text { las investigaciones. }\end{array}$ & $\begin{array}{l}\text { Persecución pena1 } \\
\text { acorde al derecho } \\
\text { penal del enemigo } \\
\text { (Zaffaroni, 2009). }\end{array}$ \\
\hline & $\begin{array}{l}\text { Persecución penal } \\
\text { orientada a1 delito } \\
\text { organizado y de cuello } \\
\text { blanco. }\end{array}$ & $\begin{array}{l}\text { Persecución penal orientada } \\
\text { a los delitos sacialmente } \\
\text { relevantes. }\end{array}$ & $\begin{array}{l}\text { Persecución penal } \\
\text { orientada a1 delito } \\
\text { clásico y de bagatela } \\
\text { (integridad fisica, } \\
\text { propiedad, etc.). }\end{array}$ \\
\hline $\begin{array}{l}\text { CASTIGO A } \\
\text { CRIMINALES }\end{array}$ & $\begin{array}{l}\text { El fin es la } \\
\text { resocialización del } \\
\text { delincuente }\end{array}$ & $\begin{array}{l}\text { Se busca aislar y en lo } \\
\text { posible resocializar a los } \\
\text { delincuentes. }\end{array}$ & $\begin{array}{l}\text { La finalidad es aislar, } \\
\text { inocuizar e intimidar } \\
\text { a la delincuencia. }\end{array}$ \\
\hline
\end{tabular}

Fuentes: Elaboración propia en base al estado de la cuestión expuesto en éste apartado.

\section{Políticas de seguridad e intereses policiales}

La mayor parte de la literatura especializada en temas de seguridad, considera que en Argentina se ha consolidado una situación dónde la policía tiene una gran autonomía respecto de las autoridades políticas y de la ciudadanía en general. ${ }^{9}$ Esta autonomía se expresa, entre otras cosas, en formulaciones de la política de seguridad que corresponden a modelos de derecha. Esta visión de la policía y de la formulación de las políticas de seguridad se remonta a varias décadas atrás, pero se instaló con fuerza en las universidades argentinas a finales de la década de los noventa, a partir de la convergencia entre investigadores sociales, periodistas y dirigentes políticos. ${ }^{10}$

Quizás la argumentación más sofisticada de este punto de vista se encuentra en los libros de Marcelo Saín (2002, 2008), en dónde se explica la perversa lógica del desgobierno político y su contracara, la autonomía policial. Según la síntesis de dos

${ }^{9}$ La literatura se diferencia luego, al evaluar las razones de esta autonomía, poniendo en juego distintos factores causales, ya sean estructurales, institucionales y/o agenciales (Costantino, 2013).

10 Algunos textos clave en ésta línea interpretativa son: el Código Procesal Penal modelo para Iberoamérica de Julio Maier (1989), el Plan de Reorganización General del Sistema Integral de Seguridad de Alberto Binder y León Arslanián (1997), el libro La bonaerense de Ricardo Ragendorfer y Carlos Dutil (1997), el informe La inseguridad policial del CELS (1998). 
seguidores de la argumentación de Saín, Antonio Camou y José Moreno (2005: 141142), «las instituciones policiales de hoy son hijas de las doctrinas de la Seguridad Nacional de ayer, pero también de intestinas y cotidianas luchas de fragmentos de poder». En efecto, «la dirigencia política y, en particular, las autoridades gubernamentales, delegan a las agencias policiales el monopolio de la administración de seguridad pública, y la institución policial posee amplios márgenes de autonomía para autogobernarse orgánica y funcionalmente. Esta autonomía está caracterizada por:

1. Una policía cuyo cuerpo institucional es unificado, con conducción centralizada y ejercida por un «Estado Mayor» cuasi castrense, con una estructura cerrada, «hiperjerarquizada» y militarizada,

2. Las prácticas institucionales están regidas y orientadas por la reproducción y preservación de la institución policial, las cuales están basadas en criterios de «mano dura» y formas de control social ilegales y extrainstitucionales,

3. El financiamiento oficial del sistema es complementado por otras fuentes ilegales,

4. La ausencia de toda modalidad e instancia de intervención o participación comunitaria en los asuntos de seguridad pública».

Siguiendo el mismo orden de ideas, León Arslanián, jurista reconocido y ex ministro de seguridad bonaerense en dos ocasiones, escribe en su último libro: «Buena parte de los males que aquejan a la agencia policial en América Latina responden a un modelo de organización anacrónico, a la ausencia de todo tipo de control y evaluación respecto de su funcionamiento, y a la falta absoluta de articulación social, todo lo cual refleja un craso abandono por parte del Estado de su misión esencial de formular políticas en materia de seguridad. (...) A su vez, semejante dejación de poder por parte del Estado, a través de gobiernos tanto legítimos como usurpadores, favoreció la autonomización policial y cristalizó un modelo de relación negocial entre la corporación y los diferentes gobiernos que pactaron con aquélla el sostenimiento de un cierto orden público que garantizaría, más que nada, condiciones de tranquilidad política a través de la represión policial de protestas políticas y sociales reivindicativas de derechos denegados» (2008: 61 у 62). ${ }^{11}$

Existen otras investigaciones que complejizan el entramado de actores que promueven las políticas de seguridad de derecha (vg. Fohrig y Pomares, 2003; Fuentes, 2005), pero que sin embargo coinciden en que la policía preferiría y tendría amplios recursos para llevar adelante este tipo de políticas. ${ }^{12}$ En efecto, los policías contarían

11 «Tal vacío ha sido cubierto de modo errático y espasmódico por reformas legislativas que hicieron eje en el reforzamiento de las penas y de los poderes policiales y en recurrentes restricciones al régimen de libertad durante el proceso, cuyo peor rostro lo expone un sistema carcelario que contiene a una cantidad de internos muy superior a la que puede admitir y cuya abrumadora mayoría son presos sin condena» (Arslanián).

12 En términos de Fuentes (2005: 5 y ss.), existe una coalición de actores pro orden o statu quo conformada por policías, gobernadores e intendentes del partido justicialista, funcionarios públicos del ministerio del interior, que explotan sus ventajas de poder para resistir los intentos de reforma del sistema policial y penal de otra coalición de actores más progresistas, compuesto por organizaciones de derechos humanos, miembros de la Unión Cívica Radical (UCR) y funcionarios públicos. 
con la capacidad de determinar que las fuerzas de seguridad sean dirigidas por profesionales (policías), que la estructura burocrática sea esencialmente jerárquica y centralizada, que se potencie la capacidad disuasoria del Estado invirtiendo más y mejores recursos para los encargados del ejercicio del monopolio de la violencia legítima, que la persecución penal deje de lado las posturas garantistas, que la cárcel se entienda como una institución destinada a castigar e inocuizar a los delincuentes.

Ahora bien, un análisis de las políticas de seguridad formuladas en las principales provincias argentinas contradice estas afirmaciones de la teoría de la autonomía policial. El estudio de estas políticas entre 1996 y la actualidad muestra que los presuntos intereses policiales no se han tenido en cuenta en muchas ocasiones, durante muchos años. Como desarrollaremos más adelante, los gobiernos de Buenos Aires, Santa Fé, Mendoza y Córdoba han implementado en distintos momentos profundas reformas en las policías y en los sistemas penales con un diagnóstico y unos objetivos contrarios a la visión policial. Sobre todo entre 1997 y 1999, se observan políticas de seguridad provinciales que comparten una serie de similitudes (Estévez, 2000: 173 y 174):

- Descabezamiento de la cúpula de conducción y separación de altos oficiales policiales.

- Creación de instancias civiles para la conducción de las políticas de seguridad y de los cuerpos policiales.

- Instauración de mecanismos de participación ciudadana como modo de democratizar los mecanismos de control de la seguridad pública.

- Creación de comisiones legislativas para la supervisión y control de los procesos de transformación.

- Promoción de instancias gubernamentales de control interno para abordar problemas de corrupción y abusos policiales.

- Fijación de principios básicos para la actuación de la policía fundados en convenciones y declaraciones internacionales y de las Naciones Unidas con el objeto de asegurar un efectivo respeto de los derechos humanos.

- Disolución de los organismos de inteligencia policiales y su reemplazo por nuevas estructuras bajo control democrático.

- Separación entre las funciones de policía de seguridad y policía de investigaciones o en función judicial, entre otras medidas tendientes a modificar la estructura de la institución policial con el criterio de especialización funcional.

- Descentralización de las Policías de Seguridad.

- Desarrollo de modificaciones en el sistemas procesal penal, lo cual en sí mismo constituía otra proceso de reforma.

- Reforzamiento de la coordinación y colaboración entre las diversas policías, y su interacción con las autoridades judiciales.

- Priorización de la formación y capacitación policial, creando una instancia ministerial para el diseño de los planes y organización de un instituto estudios superiores sobre seguridad pública.

Si bien es cierto que todos los procesos tuvieron marchas y contramarchas, con sectores de la policía y de la sociedad quejándose y resistiéndose a medidas determinadas, los gobiernos provinciales pudieron llevar adelante acciones e instituciones nuevas que transformaron sustancialmente al sistema de seguridad y que perduraron en el tiempo. En el caso de Buenos Aires y Santa Fe, por ejemplo, los gobiernos provincia- 
les llevaron adelante reformas de izquierda no sólo entre 1996 y 1999 sino también entre 2004 y 2007. En la provincia de Mendoza, un acuerdo interpartidario logró que la reforma de 1998 perdurara una década. La política de seguridad de Córdoba no sucumbió al discurso de la mano dura sino hasta la gestión de De la Sota.

En efecto, considero que las variaciones en los tipos de políticas de seguridad provinciales prueban de forma convincente que la policía no tiene el interés común ni la capacidad colectiva para convertirse en un actor importante en la formulación del tipo de política de seguridad. De lo contrario, no podrían haber existido tantas políticas de seguridad, muchas de ellas que perduraron varios años, contrarias a los intereses policiales. Ahora bien, ¿Cómo se explican los cambios en las políticas de seguridad provinciales? ¿Se pueden explicar a través de una lógica de actores? Y en ese caso, ¿cuáles serían los actores relevantes, sus intereses y estrategias?

\section{Gobernadores, planes de campaña y políticas de seguridad}

\section{La teoría}

La hipótesis fundamental de este trabajo es que el ejecutivo provincial, y no la policía, es el actor ${ }^{13}$ que tiene las facultades y el interés de formular una política de seguridad determinada (de izquierda o de derecha) según su plan de campaña. A la vez, este plan de campaña está condicionado en gran medida por la ideología del ejecutivo nacional y la ubicación del elector medio. Si tenemos en cuenta estos factores, podremos acercarnos bastante a la comprensión de la formulación de las políticas de seguridad provinciales.

Como señalan Steven Calabresi (1995: 73-74) y Elena Kagan (2000: 2334 y ss.), los ejecutivos suelen ser los actores cruciales de la mayoría de las políticas públicas en las democracias modernas, pues las Constituciones los posicionan para recibir la máxima presión del electorado vía votos y opinión pública, y para ejercer la máxima influencia sobre la administración en función de dicha presión. ${ }^{14}$ En el caso de la direc-

${ }^{13}$ Si bien compartimos las críticas clásicas a los enfoques explicativos en ciencia política basados en actores racionales (March y Olsen, 1984) consideramos que en muchos casos, dichos enfoques sirven a la construcción de teorías parsimoniosas que permiten explicar variaciones importantes en las políticas públicas (ver nota 6, Sabatier, 2010: 11 y Costantino, 2013: 18-29).

${ }_{14}$ Sobre el primer punto hay dos cuestiones a tener en cuenta: la unitariedad del ejecutivo y el mecanismo de su selección. La unitariedad es un primer rasgo que favorece la visibilización y la responsabilización del ejecutivo por parte del electorado y de los medios de comunicación. Por otro lado, el mecanismo de selección del Presidente (y del gobernador) refuerza la idea del mandato y la responsabilidad de representar la voluntad general, pues es el único cargo elegido por una mayoría nacional (o provincial), por un tiempo determinado. Sobre el segundo punto hay que notar que sólo el ejecutivo, de todos los actores en competencia por dirigir o influenciar a la burocracia, es quien tiene la energía para generar cambios sustantivos y coherentes en la gestión de las políticas públicas. Esta energía se deriva de las siguientes razones: a) Es un actor unitario y jerárquico. b) Su jurisdicción se extiende a través de toda la administración del Estado (o por lo menos del poder ejecutivo). c) Por los mecanismos de dirección y control que tiene sobre sus subordinados puede recompensar o castigar rápida y sustancialmente a los funcionarios sospechosos de un delito o de una negligencia (vg. poder de designar, reubicar y remover a los funcionarios, gestión del dinero presupuestado, poder reglamentario para gestionar la burocracia, etc.). 
ción y la supervisión de la política de seguridad argentina, el diseño federal posiciona y faculta al ejecutivo provincial para ser el primer responsable de la gestión del sistema policial y penal de su jurisdicción.

Ahora bien, aceptamos que los ejecutivos provinciales son los cargos fundamentales para comprender los cambios en la administración pública a nivel agregado, pero ¿por qué eligen formular políticas de derecha o de izquierda? $\mathrm{O}$ en otras palabras, ¿cómo entendemos que entre 1996 y 1999 los gobiernos provinciales eligen políticas de seguridad de izquierda? ¿Por qué, luego, las trayectorias se diferencian pero todas tendiendo a la derecha? ¿Por qué, durante la presidencia de Kirchner, en Buenos Aires y Santa Fé sucede una vuelta hacia los modelos seguritarios de izquierda? ¿Por qué desde 2008 el discurso seguritario de los gobernadores comienza a endurecerse nuevamente?

Coincidiendo con una postura ya clásica (Schumpeter, 1942; Downs, 1957; Blumenthal, 1982), considero que la respuesta hay que buscarla en los intereses electorales de los ejecutivos provinciales. Como sostienen Ornstein y Mann (2000: 8i), las decisiones gubernamentales de los ejecutivos tienen como fin continuo y prioritario sacar ventaja a los principales adversarios políticos para ganar elecciones. Las decisiones gubernamentales apuntan a ganar votos, cargos clave y financiación (del sector público y/o privado) a los competidores más peligrosos para cumplir su objetivo. Los ejecutivos están en una campaña permanente, que no para en ningún momento de su gestión, de manera que sus consultores de marketing político están continuamente diseñando políticas que transmitan el mensaje correcto a los actores políticos cruciales y al electorado para sacar ventaja a sus competidores respecto de la obtención de votos, apoyos políticos y recursos económicos. ${ }^{15}$

En las provincias argentinas, el cálculo del plan de campaña de los gobernadores tiene dos condicionantes clave que los afectan de manera diferente según el armado político del gobernador ${ }^{16}$ y las finanzas provinciales: i) la posición ideológica del ejecutivo nacional; ii) y la posición ideológica del elector medio. Veamos por qué:

i) Por la estructura federal y el acuerdo fiscal argentino, los gobernadores necesitan coordinar sus acciones con el ejecutivo nacional para llevar adelante políticas públicas y ganar elecciones, sobre todo si los recursos económicos, la popularidad y los apoyos políticos del Presidente son altos. En efecto, la debilidad presupuestaria provincial y la centralidad mediática del Presidente generan fuertes incentivos para que el gobernador elabore políticas públicas similares o cercanas al discurso del ejecutivo nacional, cuando el presidente cuenta con los recursos de poder mencionados.

ii) Ahora bien, cuando el Presidente es débil en recursos fiscales y popularidad, el gobernador tiene fuertes incentivos en proponer políticas que se alejan del discurso del ejecutivo nacional y se acercan a la opinión pública crítica del gobierno. Es importan-

15 Ver nota 5.

16 La historia del armado político del gobernador es importante porque una vez que un líder ha colocado su «ideología» en el «mercado» no puede abandonarla repentinamente o alterarla radicalmente sin provocar desconfianza en los votantes y conflictos con sectores aliados. Parafraseando el trabajo clásico de Anthony Downs, ningún líder puede permitirse una reputación deshonesta u oscura. 
te notar que la ubicación ideológica de la media electoral se convierte en un factor más importante en la medida que los recursos y la popularidad del Presidente decaen, pues el Gobernador buscará los recursos que no encuentra en el ejecutivo nacional acercándose al electorado crítico de este.

De lo dicho se desprenden las siguientes expectativas de observación respecto de la política de seguridad de los gobernadores, que varía en cierta medida según el armado político del gobernador y la fortaleza o debilidad de las finanzas provinciales:

1) Si el Presidente tiene altos niveles de popularidad y recursos fiscales, el Gobernador elaborará un plan de campaña que llevará adelante una política de seguridad cercana a la ubicación ideológica del poder ejecutivo nacional.

2) Si el presidente no cuenta con los recursos mencionados, el Gobernador elaborará un plan de campaña que impulse una política de seguridad cercana a la ubicación ideológica del votante medio.

\section{Los casos}

Las expectativas de mis hipótesis son validadas por la contrastación en las provincias que analizo. Como señalé anteriormente, todos los gobiernos provinciales formularon, de manera más o menos consistente, políticas de seguridad progresistas durante la segunda gestión del Presidente Menem. Esto se explica, según mi marco teórico, porque en éste período los recursos de poder del Presidente (económicos, en apoyos políticos y popularidad) disminuyeron sustancialmente respecto a la primera gestión, y en consecuencia se convirtió en «racional» que los gobernadores elaborasen planes de campaña apuntando al electorado mayormente crítico del menemismo, que se ubicaba a la izquierda de las posiciones del gobierno nacional, y especialmente en materia seguritaria. Durante éste período, Eduardo Duhalde ${ }^{17}$, Jorge Obeid ${ }^{18}$, Arturo Lafalla ${ }^{19}$ y Ramón Mestre ${ }^{20}$ implementaron medidas asociadas a la dirección civil de la policía,

17 La política de seguridad de Duhalde tuvo como medidas clave los nombramientos de Eduardo De Lazzari, Luis Lugones y León Arslanián en la cartera de seguridad, las purgas policiales extendidas, y la implementación de las siguientes normas: decreto 12/96 (de emergencia policial), leyes 11.868 (creación del Consejo de la Magistratura), 11.922 (nuevo Código Procesal Penal acusatorio), decreto 4506/97 y ley 12.068 (de intervención de la Policía Bonaerense), ley 12.069 (creación del Instituto de Política Criminal y Seguridad), 12.154 (de Seguridad Pública) y 12.155 (de Organización de las Policías de la Provincia de Buenos Aires).

${ }^{18}$ En la Provincia de Santa Fe, las medidas clave de la nueva política de seguridad fueron la designación de Roberto Rosúa para dirigir la cartera de seguridad, la creación de juntas barriales de seguridad comunitaria, la modificación de los sistemas de reclutamiento y formación policial, la creación de la Dirección Provincial de Asuntos Internos (DPAI), y la ley de Organismos de Seguridad Pública de la Provincia de Santa Fe (González, 2007).

19 En Mendoza, la «Reforma Estructural del Sistema Provincial de Seguridad Pública», en esencia similar al espíritu y esquema organizativo del dela provincia de Buenos Aires, se implementó con las leyes provinciales 6651, 6652 y 6653 (Estévez, 2000).

20 Según Estévez, el gobierno de Córdoba llevó adelante desde 1995 una reforma del sistema de seguridad que a diferencia de las llevadas a cabo en las provincias de Mendoza, Santa Fe y Buenos Aires se 
a la potenciación de los mecanismos de accountability judicial y legislativo sobre las fuerzas de seguridad, a la creación de mecanismos de participación ciudadana sobre temas de seguridad, etc.

La llegada de De la Rúa a la presidencia implicó la instalación de un gobierno nacional débil, que a los pocos meses fue cuestionado en su capacidad de mantener el orden interno ${ }^{21}$. Los gobernadores provinciales, sobre todo los peronistas, se distanciaron en diferentes grados pero de manera constante de las posiciones tomadas desde el gobierno nacional, formulando declaraciones e implementando medidas que respondían a las crecientes demandas de orden y seguridad. En el caso bonaerense, Carlos Ruckauf puso en el centro de su plan de campaña la lucha contra la delincuencia que aquejaba a los bonaerenses, y la necesidad de alejarse de las posturas progresistas de la Alianza en esta materia ${ }^{22}$. Carlos Reuteman y José Manuel De la Sota también dejaron de implementar medidas progresistas en materia de seguridad, pero articularon un discurso más moderado que el Gobernador bonaerense ${ }^{23}$. La crisis de diciembre de 2001 y la caída de De la Rúa fueron seguidas por la vuelta del peronismo a la presidencia, convirtiendo a Eduardo Duhalde en el primero entre sus pares gobernadores. Desde la presidencia de la nación, Duhalde articuló una alianza frágil con De la Sota, Reutemann y Felipe Solá, que dejó de lado el discurso de la mano dura asociado al neoliberalismo menemista, pero también la profundización de las reformas policiales de izquierda que fogoneaban los sectores más progresistas de la Alianza.

El período de Néstor Kirchner en la presidencia de la nación marca un momento diferente pues, por primera vez en una década, el gobierno nacional dispuso de una alta popularidad y de un creciente poder en recursos económicos y en apoyos políticos. A pesar del aumento paulatino de la preocupación por la seguridad, sus posturas de centroizquierda fueron escuchadas y compartidas por los gobernadores de Buenos Aires, Santa Fe y Mendoza. En Buenos Aires, Felipe Solá designó a León Arslanián para que

caracterizó por haber sido «progresiva y hasta silenciosa». Algunas de las medidas clave de este proceso reformista gradual fueron la ley 8.520 (modificatoria de las leyes 6.701/62, orgánica policial y 7.826/89 ley orgánica del Ministerio Público) que crea la policía judicial, y la ley 8.574 que implementa el Programa de Prevención del Delito y Seguridad Ciudadana.

${ }^{21}$ Desde su llegada al gobierno, el Presidente De la Rúa planteó como objetivo prioritario del inicio de su gestión el enviar buenas señales macroeconómicas a los mercados internacionales para promover una nueva ola de ingresos de capitales que motorizara el crecimiento nacional como lo había hecho entre 1996 y 1997 (Leiras, 2007: 168 y ss.). Entre las medidas requeridas para ello se encontraban los ajustes presupuestarios dispuestos por el equipo económico, un piso de transferencias de recursos de origen nacional a las provincias y una reforma en el régimen de contrato de trabajo. El gobierno aliancista tuvo problemas para negociar con los gobernadores todas estas medidas, pero especialmente la última terminó con un escándalo de corrupción en el Senado que implicaba directamente a funcionarios del Presidente. En Octubre del 2000, con solo 10 meses de gestión, renunciaba el vicepresidente Carlos «Chacho» Álvarez y la Alianza oficialista quedaba casi quebrada.

${ }^{22}$ Algunas medidas que expresan de manera clara la política seguritaria de derecha de Carlos Ruckauf son los nombramientos de Aldo Rico, Orestes Verón y Casanovas en las carteras de seguridad y justicia, la reincorporación de funcionarios policiales cesanteados, la implementación de las leyes 12.405 (de reforma del Código Procesal Penal) y 12.543 (de reforma del Código de Ejecución Penal). También el decreto premiando en efectivo a los policías que actuaran con arrojo contra los delincuentes.

${ }^{23}$ Para el caso de Santa Fe, cfr. González, 2007. 
ocupase por segunda vez el cargo de Ministro de Seguridad y para que retomase los proyectos reformistas que había iniciado en $1998^{24}$. Jorge Obeid, en Santa Fe, también nombró a su ex ministro Roberto Rosúa para insistir con el discurso seguritario de su primera gestión, y para llevar adelante las reformas iniciadas entonces ${ }^{25}$. Julio Cobos, el gobernador mendocino, continuó apelando al acuerdo seguritario consensuado por las fuerzas políticas de su provincia, el cual tenía un claro tinte progresista ${ }^{26}$. El caso de De la Sota es más complejo y se distingue, pues es el único gobernador que se acercó al discurso de derecha de Juan Carlos Blumberg en ésta época (Schaefer y Morales, 2013). Este acercamiento puede comprenderse en el contexto del conflicto que el gobernador cordobés tuvo con Kirchner desde el inicio de la gestión presidencial de éste.

Finalmente, la presidencia de Cristina Fernández se caracteriza por el deterioro de la popularidad y de las finanzas nacionales de manera pronunciada hasta 2010 , y por el aumento de un electorado crítico con posturas de centroderecha. Durante esta época es claro el corrimiento de todos los gobernadores hacia un discurso más duro en materia seguritaria. El caso bonaerense es el más conocido. Las medidas del Gobernador Scioli implicaron un claro giro a la derecha que se fue profundizando hasta finales de $2010^{27}$. En Mendoza, el gobernador Jaque, y su ministro de seguridad Carlos Ciurca, impulsaron un plan con el slogan de mano firme, nuevas leyes punitivas y más policías en la calle ${ }^{28}$. El gobernador Schiaretti continuó con la política de seguridad de De la Sota, aumentando significativamente el presupuesto del área, a través de la incorporación de agentes, de equipamiento técnico y de armas. Este sector del Estado provincial fue el que más personal incorporó durante su gestión: 8895 efectivos (Schaefer y Morales, 2013).

${ }^{24}$ Las principales medidas de la nueva política de seguridad fueron, además del nombramiento de León Arslanián en la cartera de seguridad y las repetidas purgas policiales, la promulgación de las leyes 13.188 (de emergencia policial), 13.201 (de personal de policías) y 13.482 (de organización de las policías).

25 Además de la designación de Rosúa, otras dos medidas clave fueron el nombramiento de la Dra. Leyla Perazzo como jefa de la policía, y la promulgación de la ley 6.769 en marzo de 2006.

${ }^{26}$ El gobierno de Cobos tuvo como consultores en seguridad a especialistas del Instituto Latinoamericano de Seguridad Democrática (ILSED), y a miembros del partido justicialista y demócrata cristiano que cristalizaban el compromiso de profundizar la reforma de finales de los noventa (cfr. Diario Uno, 2005; Los Andes, 2005).

27 Algunas medidas ejemplares fueron los nombramientos de Stornelli y Casal en las carteras de seguridad y justicia, el establecimiento del cargo de jefe de policía (Decreto 74/07), la reestructuración jerárquica de la institución y la reglamentación de un nuevo estatuto policial (Ley 13.982), las leyes 13811, 13812 y 13943, de reformas de los Códigos Procesal y de Ejecución Penal, la desactivación de varios programas progresistas de la gestión Arslanián como la Policía 2 y el Plan CERCA.

${ }^{28}$ Las nuevas leyes incluían el aumento de penas y la incorporación de nuevas faltas y delitos, la ley de allanamientos más ágiles. 
Cuadro 2: Orientación de la politica de seguridad según recursos de poder del presidente

\begin{tabular}{|c|c|c|c|c|c|c|c|}
\hline Año & $\begin{array}{c}\text { Poder del } \\
\text { presidente }\end{array}$ & $\begin{array}{c}\% \\
\text { Popularidad } \\
\text { presidente* }\end{array}$ & $\begin{array}{c}\text { Apoyos } \\
\text { politicos al } \\
\text { presidente** }\end{array}$ & $\begin{array}{c}\text { Posib. } \\
\text { reeleccion } \\
\text { presidente }\end{array}$ & $\begin{array}{c}\text { Recursos } \\
\text { Fiscales*** }\end{array}$ & \multicolumn{2}{|c|}{$\begin{array}{c}\text { Orientación Politica } \\
\text { de Seguridad }\end{array}$} \\
\hline 1996 & Bajo & 26 & Medio & No & Bajo & Vot. Medio & Izquierda \\
\hline 1997 & Bajo & 24 & Medio & No & Bajo & Vot. Medio & Izquierda \\
\hline 1998 & Bajo & 33 & Bajo & No & Bajo & Vot. Medio & Izquierda \\
\hline 1999 & Bajo & 32 & Bajo & No & Bajo & Vot. Medio & Izquierda \\
\hline 2000 & Bajo & 34 & Bajo & $\mathrm{Si}$ & Bajo & Vot. Medio & Derecha \\
\hline 2001 & Bajo & 14 & Bajo & $\mathrm{Si}$ & Bajo & Vot. Medio & Derecha \\
\hline $2002-5 / 2003$ & Bajo & 6 & Medio & $\mathrm{Si}$ & Bajo & Vot. Medio & Centro \\
\hline $5 / 2003-2004$ & Alto & 66 & Alto & $\mathrm{Si}$ & Alto & Ideol. Pres & Izquierda \\
\hline 2005 & Alto & 61 & Alto & $\mathrm{Si}$ & Alto & Ideol. Pres & Izquierda \\
\hline 2006 & Alto & 64 & Alto & $\mathrm{Si}$ & Alto & Ideol. Pres & Izquierda \\
\hline 2007 & Alto & 55 & Alto & $\mathrm{Si}$ & Medio & Ideol. Pres & Izquierda \\
\hline 2008 & Medio & 34 & Medio & $\mathrm{Si}$ & Medio & Vot. Medio & Derecha \\
\hline 2009 & Medio & 25 & Medio & $\mathrm{Si}$ & Bajo & Vot. Medio & Derecha \\
\hline 2010 & Alto & 35 & Alto & $\mathrm{Si}$ & Medio & Vot. Medio & Centro \\
\hline 2011 & Alto & 59 & Alto & $\mathrm{Si}$ & Bajo & Ideol. Pres & Centro \\
\hline
\end{tabular}

Fuentes: Elaboración propia: (*) La popularidad presidencial es calculada de acuerdo a los resultados de las encuestas de opinión sobre la aprobación presidencial de las consultoras argentinas IPSOS (1996-2002) y Poliarquía (2003-2011). (**) Los apoyos políticos al presidente son calculados a partir de un índice que toma los apoyos de los ejecutivos subnacionales contándolos según el peso electoral de sus jurisdicciones. (***) Los recursos fiscales son estimados según los análisis de los resultados fiscales primarios de Gay y Escudero (2010) e Instituto de Estudios Económicos (2012). (****) La orientación de la política de seguridad se acerca a la posición ideológica del ejecutivo nacional o a la del votante medio, cuya opinión ponderamos según los datos de Latinobarómetro 1995-2010.

\section{Conclusiones}

En un libro muy interesante publicado en 2008, Sabina Frederic advertía sobre la insistencia de la visión experta en considerar a la «institución policial» como una institución de carácter cerrado, autónomo y corrupto. Según la autora, esta visión experta no se ajusta a la compleja realidad de dicha burocracia y es poco fructífera en términos de la producción de conocimiento. Para peor, trata a las fuerzas de seguridad como un cuerpo extraño respecto a la política y a la sociedad, lo que genera nuevas y más profundas contradicciones entre los actores políticos, burocráticos y sociales, negando saberes, pertenencias y vínculos constitutivos del trabajo policial cuyas condiciones de existencia no son sólo policiales.

Frederic señala complementariamente que las ciencias sociales deberían apostar a la introducción de enfoques relacionales, que muestren a los policías en relación con otros actores, y a los propios policías como actores atravesados y definidos por diferentes vínculos y actividades, dentro y fuera de la policía. «Creemos que los científicos sociales estaremos así en mejores condiciones para desafiar los prejuicios dominantes, formular un diálogo sustantivo con los agentes que integran las fuerzas armadas y ofrecer un conocimiento cuya contribución a la agenda de gobierno consista en 
determinar la sustentabilidad de las políticas atendiendo al punto de vista de todos los implicados, incluyendo claro a los policías» (Frederic, 2008: 89).

Consideramos que las apreciaciones de Frederic son muy pertinentes para construir investigaciones que ayuden a formular e implementar políticas de seguridad tanto sustentables como equitativas en nuestro país. En este sentido, nuestro artículo pretendió aportar algunas ideas que dan cuenta del juego estratégico que está detrás de la formulación de las políticas de seguridad provinciales, juego estratégico que condiciona la dirección y el funcionamiento del sistema policial y penal. En efecto, en el tercer apartado desarrollamos la hipótesis principal de nuestra investigación: los gobernadores son los actores que tienen las facultades de formular una política de seguridad de izquierda o de derecha según su plan de campaña, el cual responde a otros condicionantes que no son los intereses policiales: principalmente los intereses del ejecutivo nacional y la ubicación del elector medio. Estos elementos son los que afectan en gran medida las acciones que hacen a la formulación de la política de seguridad, como la elección de la cúpula burocrática, los cambios en la estructura legal y reglamentaria del sistema policial y penal, y las inversiones estratégicas en recursos económicos y humanos para el cumplimiento de los programas policiales y penales.

Las pruebas recabadas en los casos de Buenos Aires, Córdoba, Santa Fe y Mendoza entre 1996 y 2011 dan cuenta que la hipótesis es explicativa. En el apartado anterior describimos cómo los gobernadores formularon políticas de seguridad progresistas durante la segunda presidencia de Menem, reorientaron sus políticas de seguridad a la derecha durante la presidencia de De la Rúa, y volvieron a correrse a una postura más progresista con la llegada de Duhalde al ejecutivo nacional. Estos tres momentos se caracterizan por la existencia de presidentes con bajos recursos de poder, y políticas de seguridad que se orientan según los cambios ideológicos del elector medio. ${ }^{29}$ La llegada de Kirchner al ejecutivo nacional marca por primera vez, en mucho tiempo, la presencia de un Presidente con altos recursos de poder e ideología progresista. No es casual que durante su gestión los gobernadores orientasen la formulación de sus políticas de seguridad hacia la izquierda ${ }^{30}$. Finalmente, la presidencia de Cristina Fernández se caracteriza por contar con recursos de poder decrecientes entre 2008 y finales de 2010, momento en que su popularidad aumenta de forma notable, y la reelección parece al alcance de la mano. De manera consistente con nuestra hipótesis, durante esta presidencia, los gobernadores comienzan sus gestiones tomando medidas seguritarias de centro derecha para, al finalizar sus mandatos, incluir medidas más progresistas ${ }^{31}$.

Este juego estratégico de los gobernadores, detrás de la formulación de las políticas de seguridad provinciales, ayuda a comprender la autonomía relativa de la policía

${ }^{29}$ La política de seguridad de Iglesias es la excepción a ésta tendencia. Excepción que puede explicarse por el armado político previo del gobernador mendozino, que se basa en actores progresistas de la Alianza.

${ }^{30}$ La política de seguridad de De la Sota es la excepción a ésta tendencia. Excepción que puede explicarse por el armado político previo del gobernador cordobés, y por el cortocircuito con Kirchner desde el inicio de la gestión presidencial.

${ }^{31}$ La política de seguridad de Binner es la excepción a ésta tendencia. Esta excepción también puede explicarse teniendo en cuenta el armado político previo del gobernador santafesino. 
y del sistema penal. Muestra cómo policías, fiscales, defensores, jueces y penitenciarios realizan sus tareas atravesados y condicionados por los discursos y las medidas del juego político. Por supuesto, la reconstrucción de dicho juego estratégico no agota la polémica sobre los alcances precisos de la autonomía policial en todas sus aristas e implicancias. Pero sí descubre la centralidad de los ejecutivos, sus planes de campaña, y la relación con el presidente y la «opinión pública», en la elaboración de medidas que afectan sustancialmente el funcionamiento policial y penal para la gestión de la seguridad. Consideramos que dicha revelación puede contribuir a la construcción de los enfoque relacionales sugeridos por Frederic, enfoques que nos salvarían de prejuicios como los mencionados anteriormente, y que facilitarían el diálogo razonable y responsable entre los actores clave de los procesos de formulación e implementación de las políticas de seguridad.

Con la meta de continuar esta línea de trabajo, las próximas investigaciones deberán profundizar la nueva perspectiva teórica que focaliza en el rol de los ejecutivos y sus planes de campaña, avanzando no sólo en la explicación de la formulación de las políticas de seguridad en otras provincias y en otros períodos históricos (Frederic, 1984-2015), sino también en su eficacia desde el punto de vista de la sustentabilidad y la equidad mencionadas. Seguramente este último tipo de investigación implicará el gran desafío de incluir en el análisis nuevos actores y coyunturas, pero sin poner en juego la parsimonia mínima que requiere cualquier explicación útil.

\section{Bibliografía}

Aguilar Villanueva, L. (1992). La hechura de las politicas. Miguel Ángel Porrúa Editor, México.

Álvarez et al. (2013). Estado, democracia y seguridad ciudadana: apuntes para el debate. PNUD Argentina, Buenos Aires.

Arslanián, L. (2008). Un cambio posible: delito, inseguridad y reforma policial en la provincia de Buenos Aires. Edhasa, Buenos Aires.

Barreneche, O. (2009). «Por mano propia. La justicia policial de la provincia de Buenos Aires en el primer peronismo», en Cuadernos del CISH, nº 25, pp. 123-152. Sociohistórica, Buenos Aires.

Barreneche, O. (2010). «De brava a dura: la policía de la provincia de Buenos Aires durante la primera mitad del siglo XX», en Cuadernos de Antropología Social, no 32, pp. 31-5.6

Blumenthal, S. (1982). The permanent campaign. Simon and Schuster, New York.

Calabresi, S. (1995). «Some normative arguments for the unitary executive», en Arkansas LawReview, $\mathrm{n}^{\circ} 48$, pp. 23.

Camou, A y Moreno, J. (2005). «Crisis, reforma y contrarreforma. El sistema de seguridad pública de la provincia de Buenos Aires: Vultura Institucional, los actores políticos y la misión de los reformadores (1997-1999)», en Tiempos Inclementes. Culturas Policiales y Seguridad Ciudadana. Editado por Gregorio Kaminsky. Ediciones de la UNLA, Buenos Aires.

Carrión, F. (2007). «Reforma policial y política: un complejo entramado de compromisos, resistencias y condiciones de posibilidad», en Revista Latinoaméricana de Seguridad Ciudada$n a$, Ecuador. 
Centro de Estudios de la Justicia en las Américas. (2005). Reformas procesales penales en América Latina: Resultados del Proyecto de Seguimiento. CEJA, Chile.

Centro de Estudios Legales y Sociales. (1998). La inseguridad policial. Violencia de las fuerzas de seguridad en la Argentina. Centro de Estudios Legales y Sociales (CELS), Buenos Aires - Argentina.

Clarín. (2013). «El conflicto policial ya afectó a 17 provincias y hay aqueos», en Accessed March 16, 2014. En: http://www.clarin.com/politica/conflicto-policial-afecto-provinciassaqueos_0_1045095545.html.

Costantino, G. (2013). Gobernadores y políticas de seguridad en la provincia de Buenos Aires (1996-2011). Tesis de Doctorado en Ciencia Política, Universidad Nacional de San Martín, Buenos Aires.

Dewey, M. (2012). «Illegal police protection and the market for stolen vehicles in Buenos Aires», en Journal of Latin American Studies, vol. 44, nº 04, pp. 679-702.

Diario Los Andes. (2005). «Cornejo reemplaza a grillo En Seguridad - Diario Los Andes.», en Accessed May 2, 2014. En: http://www.losandes.com.ar/notas/2005/2/1/politica142772.asp.

Diario Uno. (2005). «Uno: Especialistas presentaron ideas para la seguridad de Mendoza.», en Accessed May 2, 2014. En: http://www.uncu.edu.ar/novedades/index/uno-especialistaspresentaron-ideas-para-la-seguridad-de-mendoza.

Diez Ripollés (2008). «La política legislativa penal iberoamericana a principios del Siglo XXI», en Política Criminal: Revista Electrónica Semestral de Políticas Públicas En Materias Penales, $\mathrm{n}^{\mathrm{0}}$ 5, pp. 7-37.

Diez Ripollés. (2004). «El nuevo modelo penal de la seguridad ciudadana», en Revista Electrónica de Ciencia Penal y Criminología, no 6. En: http://scholar.google.es/scholar?q=Diez + Ripoll $\% \mathrm{C} 3 \% \mathrm{~A} 9 \mathrm{~s}+2004 \& \mathrm{btnG}=\& \mathrm{hl}=$ es\&as sdt $=0 \% 2 \mathrm{C} 5$.

Downs, A. (2002). «Teoría económica de la acción política en una democracia», en AAVV, Diez Textos Básicos de Ciencia Política. Ariel, Barcelona.

Dutil, C y Ragendorfer, R. (1997). La bonaerense. Editorial Planeta, Buenos Aires.

El País. (2014). «La reforma urge». Accessed March 16, 2014. En http://www.pagina12.com.ar/diario/elpais/1-237932-2014-01-17.html.

Estévez, E. E. (2000). «Reforma de sistemas de seguridad pública e investigaciones judiciales: tres experiencias en la Argentina», en Colección, nº10, pp. 139-182.

Föhrig, A y Pomares, J. (2006). «Las reformas policiales desde las teorías del cambio institucional: Los intentos de transformación de la policía de Buenos Aires.», en Participación ciudadana y reformas en América del Sur. Editado por Hugo Fruhling y Candina, Azun. Santiago: CED Centro de Estudios para el Desarrollo.

Frederic, S. (2008). Los usos de la fuerza pública. Debates sobre militares y policías en las ciencias sociales de la democracia. Editorial: UNGS - Biblioteca Nacional.

Frederic, S. (2009). «Comentario a 'La dinámica de delito-policía en los procesos de reforma policial», en Seguridad y ciudadanía. Editado por Gabriel Kessler. Edhasa, Buenos Aires.

Fuentes, C. (2005). Contesting the iron fist. Advocacy networks and police violence in Chile and Argentina. Routledge.

Gay y Escudero. (2010). El resultado fiscal estructural en la Argentina. En: http://www.eclac.cl/ilpes/noticias/paginas/1/41751/Gay_Escudero_2010_ARG_doc.pdf

González, G. (2007). «Reforma policial y política: Un complejo entramado de compromisos, resistencias y condiciones de posibilidad», en Revista Latinoaméricana de Seguridad Ciudadana, Ecuador.

Instituto de Estudios Económicos (2012). «Finanzas Públicas.», en Temas Públicos, nº 7, Buenos Aires. 
Jordana, J. (1995). «El análisis de los policy networks: ¿Una nueva perspectiva sobre la relación entre políticas públicas y Estado?», en Gestión y Análisis de Políticas Públicas, $\mathrm{n}^{\circ} 3$.

Kagan, E. (2000). «Presidential administration», en Harvard Law Review, n 114, pp. 22-45.

Kaminsky, G. (2005). Tiempos inclementes: culturas policiales y seguridad ciudadana. Ediciones de la UNLA, Buenos Aires.

Kessler. (2009). Seguridad y ciudadanía: nuevos paradigmas y políticas públicas. Edhasa, Buenos Aires.

King, G. (2000). El diseño de la investigación social: la inferencia científica en los estudios cualitativos. Alianza Editorial, Madrid.

La Nación. (2013). «La protesta policial con mayor alcance de la historia Argentina», en laNacion.com. En: athttp://www.lanacion.com.ar/1646173-la-protesta-policial-con-mas-alcance-de-la-historia-argentina

March, J. G y Olsen, J. P. (1983). «The new institutionalism: organizational factors in political life.», en American Political Science Review, pp. 734-749.

Marsh, D y Rhodes, R.A.W. (1992). Policy networks in British Government. Clarendon Press, Oxford.

Ornstein y Mann. (2000). The permanent campaign and its future. American Enterprise Institute?: Brookings Institution, Washington, D.C.

Palmieri, G y Wagmaister. (2009). «La dinámica de delito-policía en los procesos de reforma policial», en Seguridad y ciudadanía. Editado por Gabriel Kessler. Edhasa. Buenos Aires.

Peña, J. A. (2013). «Políticas públicas de defensa», en Jordán, J. (Coord.). Manual de estudios estratégicos y seguridad internacional. Plaza y Valdés Editores.

Pérez Cepeda, A. I. (2006). «El código penal de la seguridad: Una involución en la política criminal de signo reaccionario», en Cepeda Pérez y Bernuz Beneitez (Coord.). La tensión entre libertad y seguridad: una aproximación sociojurídica. Universidad de La Rioja.

Perfil. (2013). «Desgobierno Político y policialización de la seguridad.» Accessed March 16, 2014. En: http://www.perfil.com/elobservador/Desgobierno-politico-y-policializacion-dela-seguridad-20131214-0043.html.

Rico, J. (1997). Justicia penal y transición democrática en América Latina. Siglo Veintiuno Editores, México.

Rico, J. y Chinchilla, L. (2002). Seguridad ciudadana en América Latina hacia una política integral. Siglo Veintiuno Editores, México, D. F.

Rodrigo, R. (2013a). Las cúpulas policiales: el estudio de los jefes policiales en el caso bonaerense (2000-2012): Sobreviviendo a los procesos de cambio. Congreso SAAP.

Rodrigo, R. (2013b). Reforma y Contrarreforma policial en el caso de la Provincia de Buenos Aires (2004-2011): sus implicancias políticas. Tesis de Licenciatura en Ciencia Política. Universidad de San Andrés.

Sabatier, P. (2010). «Se necesitan mejores teorías», en: Sabatier, P. (ed.). Teorías del proceso de las políticas públicas. Proyecto Modernización del Estado, Buenos Aires.

Sain, M y Frederic, S. (2008). «Profesionalización y reforma policial: concepciones sobre las prácticas de la Policía de la provincia de Buenos Aires.», en Estado, democracia y seguridad ciudadana: apuntes para el debate, editado por PNUD Argentina, Buenos Aires.

Sain, M. (2002). Seguridad, democracia y reforma del sistema policial en la Argentina. Fondo de Cultura Económica, Buenos Aires.

Sain, M. (2008). El Leviatán azul: policía y política en la Argentina. Siglo Veintiuno Editores, Buenos Aires.

Salles Kobilanski, F. (2011). «La política comparada de las reformas policiales en América Latina: Contribuciones analíticas para el caso argentino». en Cuadernos de Seguridad, $\mathrm{n}^{\mathrm{o}} 14$, pp. 33-54 
Salles Kobilanski, F. (2013). La política subnacional de las instituciones de accountability policial en Argentina (1995-2012): actores de veto partidarios y durabilidad institucional. Tesis de Maestría en Ciencia Política, Universidad Torcuato Di Tella.

Schaefer y Morales. (2013). «Seguridad y democracia: tensiones de origen. Aportes al análisis de la política de seguridad en la provincia de córdoba», en Estudios, $\mathrm{n}^{\circ} 29$, pp. 111-131

Sozzo, D y Bailey. (2005). Seguridad y reforma policial en las Américas: experiencias y desafios. Siglo XXI Editores, México, D. F.

Zaffaroni, E. (2006). El enemigo en el derecho penal. Librería-Editorial Dykinson, Buenos Aires. 